\title{
Landscape Ecological Security Construction and Evaluation Research Based on GIS and MCR Model
}

\author{
Wensheng Deng ${ }^{1}$, Cuizhao Zhao ${ }^{2}$ and Guiying Sun $^{3}$ \\ ${ }^{1}$ Faculty of Resourcs and Environmental Science, Hubei University, No.368, Youyi Avenue, Wuhan, China, 430062 \\ ${ }^{2}$ Nanning land resources center of surveying, Mapping and geoinformation, No.3-1, Jinchun Road, Nanning, China, 530022 \\ ${ }^{3}$ Hubei Institute of Urban Planning \& Design, No.47, Zhongnan Yi Road, Wuhan, China, 430071
}

\begin{abstract}
Ecological safety is not only the primary require for human preservation and development, but also the key part of country safety. Protecting the regional ecological safety is the main job of the construction of ecological civilization in our country. Firstly, Land use temporal and spatial analysis model is established based on primary land use data in 2006, 2009, 2012 and 2015. Secondly, to create landscape ecological security pattern and ecological safety degree gets temporal and spatial distribution of ecological safety status at Yunyang District based on GIS and MCR model, which uses suitable ecological source, elevation, slope, runoff, geological disasters, and land use cover type factor. Finally, Clustering analysis method is used to divide ecological security level into high safety, middle safety and low safety areas. The research is important guiding significance in regional ecological restoration and planning.
\end{abstract}

\section{Keywords--LUCC; GIS; ecological security pattern; MCR}

\section{INTRODUCTION}

In recent years, with the accelerating urbanization, frequency and intensity of human disturbance is increasing. Wetland, forest and other ecological land use are developing. There is important influence on ecological security pattern ${ }^{[1]}$. Land use structure is violently changing, which results in changing production capacity and resilience of landscape eco-system, seriously threatening landscape ecological security ${ }^{[2]}$.Yunyang District is the core of the middle route of south-to-north water transfer project in China. Its ecological niche is an important ecological barrier of the Yangtze River basin, undertakes the important ecological security of Hanjiang river middle reaches ${ }^{[3]}$.Combining with LUCC and Ecologic principles, this paper carries out the LUCC dynamic analysis. Using the MCR model ${ }^{[4-6]}$, constructs landscape ecological security pattern and ecological security level, gets time and space distribution of ecological security at Yunyang District. It can further grasp the ecological security condition in the study area in the landscape level differences of space and time. This research of Yunyang District ecological security protection and security to provide scientific reference ${ }^{[7]}$, at the same time of fragile ecosystem restoration and reconstruction of ecological environment, the improvement of the ecological system function and has the important practical significance ${ }^{[8]}$.

\section{Profiles With the DAta IN the StUdy AREA}

\section{A. The Study Area}

Yunyang District is formerly known as yunxian county, belongs to shiyan city, hubei province, is located in the
Hanjiang River water catchment areas, $32^{\circ} 25^{\prime} \sim 33^{\circ} 15^{\prime} \mathrm{N}$, $110^{\circ} 7^{\prime} \sim 111^{\circ} 16^{\prime} \mathrm{E}$. By 2015,there is 20 towns and land area of 3832.44 square kilometers in Yunyang District.

\section{B. The Main Data Source}

There is land use change survey data in Yunyang District in 2006, 2009, 2012 and 2015, 30m spatial resolution DEM data, the geological disaster prevention plan, scenic spots, forest park, wetland nature reserve, river system and vector data and other text data materials.

\section{Data Processing and Classification}

With two adjustable data and change survey data, classification system is not unified, land use data needs to be conversed. Using the planning software tool converts four-phase land use source data to primary planning vector data Land use classification standard references to the present situation of land use classification standard and LUCC classification system of Chinese academy of sciences. Combines the local actual situation and the appropriate modified standard, land use type of study area is classified to cultivated land, garden land, forest land, grassland, urban land, rural residential areas, industrial and mining land, water and other 9 kinds. At the same time, land use attribute database is established.

\section{LAND USE TEMPORAL AND SPATIAL DYNAMIC ANALYSIS}

\section{A. Land Use Temporal Change}

Land use data preprocessing and re-classification above gets four periods land use situation maps in Yunyang District in 2006, 2009, 2012 and 2015 (figure I). Using ArcGIS spatial analysis tools gets land use structure table (table I), used for analysis of land use quantity change in Yunyang District in nearly nine years.

Land use structure had Large change in Yunyang District in recent 9 years. Figure I and Table I showed that arable land area is a trend from increasing to decreasing. From 2006 to 2012, it was increased that some unused land was reclaimed. In nearly 3 years, it was deceased that the urban construction occupied, especially highways and infrastructure. In 2006-2012, with the rapid development of population, rural residents showed a trend of increasing, nearly three years, rural residents was a trend of decreasing, urbanization, urban land area showed a trend of increasing year by year. 

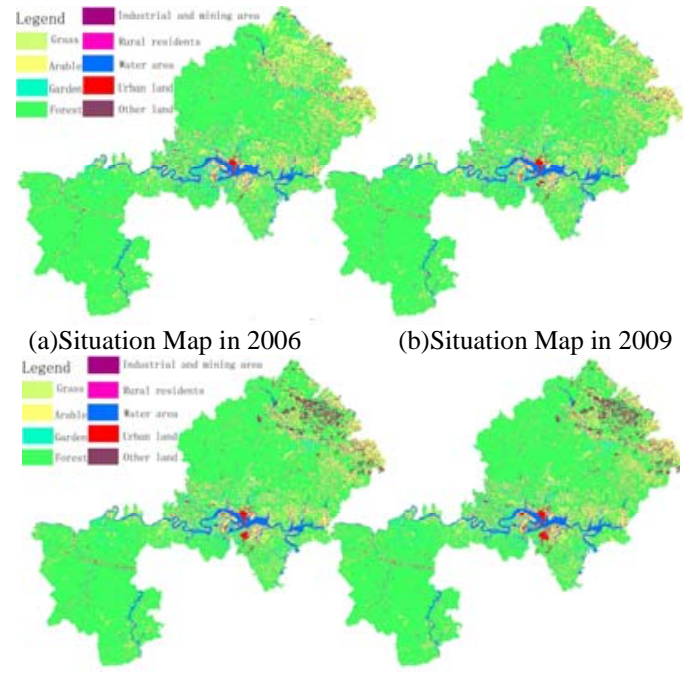

(c)Situation Map in 2012

(d)Situation Map in 2015 FIGURE I. LAND USE STATUS MAP

\section{B. Land Use Spatial Change}

Overlaying Land use data and DEM data gets average height and average slope structure (table II). It is used to analyze land use spatial change.

Table II showed that average elevation of land use structure change is not obvious. The land class type in which Area is increasing year by year, has arable land, garden land, forest land. Most of the land types of average height are relatively increasing, gradually move to high altitudes. These illustrate the development of land use intensity increasing. At the same time, average grade of land use structure change is not obvious, but other land use change relatively larger.

TABLE I. LAND USE STRUCTURE

\begin{tabular}{|c|c|c|c|c|c|c|c|c|}
\hline & \multicolumn{2}{|c|}{2006} & \multicolumn{2}{|c|}{2009} & \multicolumn{2}{|c|}{2012} & \multicolumn{2}{|c|}{2015} \\
\hline Land Type & Area/hm² & Percent & Area/hm ${ }^{2}$ & Percent & Area/hm ${ }^{2}$ & Percent & Area/hm² & Percent \\
\hline Arable & 55686.85 & 14.53 & 56443.67 & 14.73 & 56812.77 & 14.82 & 56427.22 & 14.72 \\
\hline Garden & 13189.03 & 3.44 & 13010.39 & 3.39 & 12677.06 & 3.31 & 12541.24 & 3.27 \\
\hline Forest & 270232.2 & 70.51 & 270976.9 & 70.71 & 270433.4 & 70.56 & 270187 & 70.50 \\
\hline Grass & 19623.03 & 5.12 & 17665.01 & 4.61 & 9404.75 & 2.45 & 9339.29 & 2.44 \\
\hline Urban land & 916.21 & 0.24 & 1318.27 & 0.34 & 1696.07 & 0.44 & 2059.1 & 0.54 \\
\hline Rural residents & 9233.92 & 2.41 & 9603.61 & 2.51 & 9660.77 & 2.52 & 9649.74 & 2.52 \\
\hline $\begin{array}{l}\text { Industrial and } \\
\text { mining area }\end{array}$ & 550.93 & 0.14 & 366.23 & 0.10 & 380.57 & 0.10 & 380.57 & 0.10 \\
\hline Water area & 13523.11 & 3.53 & 13402.03 & 3.50 & 13395.68 & 3.50 & 13378.76 & 3.49 \\
\hline Other land & 289.16 & 0.08 & 458.35 & 0.12 & 8783.36 & 2.29 & 9281.55 & 2.42 \\
\hline Total & 383244.4 & 100 & 383244.4 & 100 & 383244.4 & 100.00 & 383244.4 & 100.00 \\
\hline
\end{tabular}

TABLE II. AVERAGE HEIGHT AND SLOPE STRUCTURE

\begin{tabular}{|c|c|c|c|c|c|c|c|c|}
\hline \multirow{2}{*}{ Land use and land cover type } & \multicolumn{4}{|c|}{ Average height $(\mathrm{m})$} & \multicolumn{4}{c|}{ Average slope $\left(^{\circ}\right)$} \\
\cline { 2 - 8 } & 2006 & 2009 & 2012 & 2015 & 2006 & 2009 & 2012 & 2015 \\
\hline Arable & 352.97 & 353.90 & 354.17 & 354.89 & 8.14 & 8.03 & 8.07 & 8.08 \\
\hline Garden & 328.45 & 328.71 & 330.56 & 331.83 & 10.24 & 10.20 & 10.28 & 10.32 \\
\hline Forest & 594.46 & 594.89 & 595.40 & 595.68 & 18.93 & 18.94 & 18.95 & 18.95 \\
\hline Grass & 463.54 & 455.26 & 424.79 & 426.14 & 16.12 & 15.85 & 14.77 & 14.82 \\
\hline Urban land & 211.74 & 221.06 & 226.89 & 225.15 & 5.3 & 5.81 & 6.07 & 6.09 \\
\hline Rural residents & 332.84 & 335.57 & 334.78 & 334.92 & 5.41 & 5.48 & 5.47 & 5.48 \\
\hline Industrial and mining area & 319.36 & 391.01 & 395.74 & 395.74 & 8.19 & 9.78 & 9.92 & 9.92 \\
\hline Water area & 190.71 & 191.44 & 191.43 & 191.38 & 6.09 & 6.01 & 6.02 & 6.01 \\
\hline Other land & 245.21 & 243.93 & 475.26 & 464.95 & 5.95 & 6.57 & 16.24 & 15.71 \\
\hline
\end{tabular}

The biggest change of average slope is industrial and mining land and other land.

\section{BUILDING AND ANALYZING LANDSCAPE ECOLOGICAL SECURITY PATTERN}

\section{A. Minimum Cumulative Resistance Model}

Minimum cumulative resistance (MCR) model is refered that biology is necessary to overcome the minimum cumulative resistance mode through landscape ecological process. The minimum resistance value (MCR) computation formula is as follows:

$$
M C R=f \min \sum_{i=n}^{i=m}\left(D_{i j} \times R_{i}\right)
$$

In formula, $D_{i j}$ is the distance of biological units from the source $\mathrm{j}$ to the landscape unit $\mathrm{i} ; R_{r}$ is the resitance of the landscape unit i to a certain species movement.

\section{B. Definition of Ecological "Source"}

The study area is mountainous. Its sorting is between $13 \mathrm{~m}$ and $1783 \mathrm{~m}$ above sea level. Its slope size is between $0^{\circ}$ and $72^{\circ}$. This paper mainly studies the ecological land, the protection of forest land, wetland and natural scenic spot. The choice of "source" mainly is height on the $1000 \mathrm{~m}$ above sea level and forest giant plaques of more than $500 \mathrm{hm} 2$.Hanjiang River and its wetland nature reserve, and Yunyang scenic area are the "ecological source" of landscape ecological protection.

C. Construction of Single Factor Resistance Surface 
Terrain, nature reserves, surface coverage, runoff and geological disasters are the main factors affecting the landscape differentiation change. In grading of various factors, this paper is based on the related research results, at the same time, in combination with the practical situation of the study area to set the importance coefficient and value of resistance factor. The resistance factor and coefficient are worked out (table III), and the single factor resistance surface is established (figure II). The greater is the resistance value, ecological environment is fragile. The smaller is the resistance interference ability, the lower is the security level. This paper chooses the elevation, slope, runoff, geological disasters, and land use cover types for resistance factors.

\section{Comprehensive Resistance Established Below}

Combining single factor resistance surface and the weight value of table III, various factors weighted superposition calculation gets four composite surface resistance in Yunyang district in 2006-2015(figure II). Its comprehensive resistance surface can effectively reflect of ecological safety resistance degree for nearly nine years. Figure II shows that the resistance of relatively flat water area and a certain of ecological protection land is small, high mountains and steep slope areas have high resistance.

TABLE III. RESISTANCE FACTOR AND COEFFICIENT

\begin{tabular}{|c|c|c|c|c|}
\hline resistance factor & weight & Resistance grade & Partition standard & Relative resistance value \\
\hline height & $20 \%$ & $\begin{array}{l}1 \\
2 \\
3 \\
4 \\
5\end{array}$ & $\begin{array}{c}<300 \mathrm{~m} \\
300-500 \mathrm{~m} \\
500-800 \mathrm{~m} \\
800-1000 \mathrm{~m} \\
>1000 \mathrm{~m}\end{array}$ & $\begin{array}{c}10 \\
30 \\
50 \\
70 \\
100\end{array}$ \\
\hline slope & $20 \%$ & $\begin{array}{l}1 \\
2 \\
3 \\
4 \\
5\end{array}$ & $\begin{array}{c}<6^{\circ} \\
6^{\circ}-15^{\circ} \\
15^{\circ}-25^{\circ} \\
25-35^{\circ} \\
>35^{\circ}\end{array}$ & $\begin{array}{c}0 \\
5 \\
10 \\
80 \\
100\end{array}$ \\
\hline Land use cover type & $40 \%$ & $\begin{array}{l}1 \\
2 \\
3 \\
4 \\
5\end{array}$ & $\begin{array}{c}\text { Water and forest } \\
\text { grass } \\
\text { arable and garden } \\
\text { rural resident and other land } \\
\text { urban and industrial land }\end{array}$ & $\begin{array}{c}0 \\
30 \\
50 \\
70 \\
150\end{array}$ \\
\hline runoff & $10 \%$ & & & \\
\hline Disaster & $10 \%$ & $\begin{array}{l}1 \\
2 \\
3 \\
4\end{array}$ & $\begin{array}{c}\text { no } \\
\text { low } \\
\text { middle } \\
\text { high }\end{array}$ & $\begin{array}{c}10 \\
30 \\
70 \\
100\end{array}$ \\
\hline
\end{tabular}

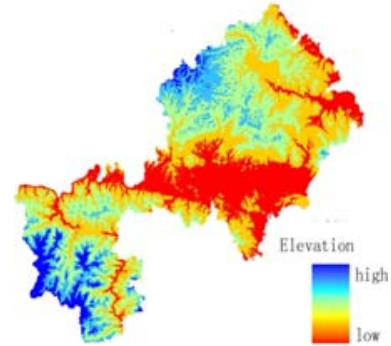

(a)Elevation resistance surface

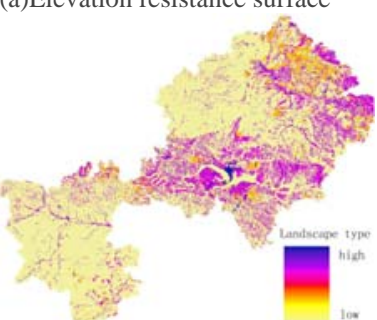

(e)Land type resistance surface in 2006

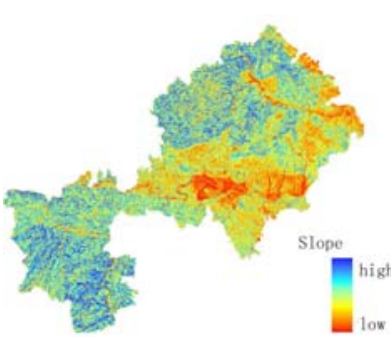

(b)Slope resistance surfac

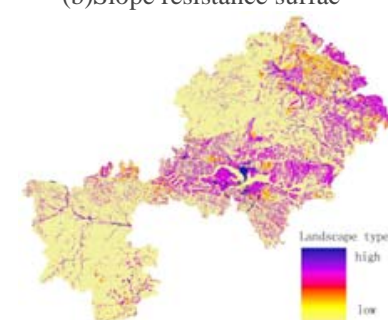

(f)Land type resistance surface in 2009

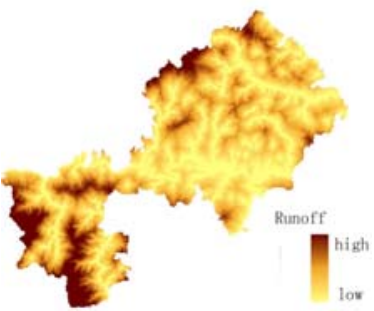

(c)Runoff resistance surface (d)Geological disasters resistance surface

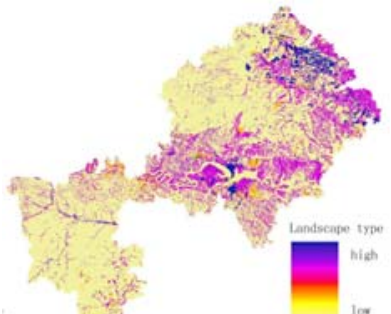
2015

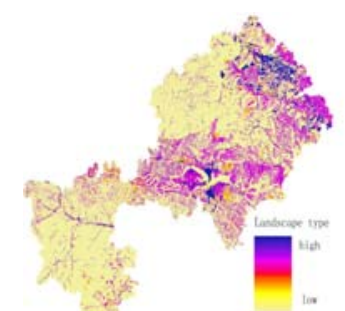

(g)Land type resistance surface in 2012 (h)Land type resistance surface in

FIGURE II. SINGLE FACTOR RESISTANCE SURFACE MAP

E. 


\section{Building Ecological Security Pattern}

According to above four comprehensive resistance and ecological "source", combined with GIS cost distance spatial analysis tools, building the MCR model gets four comprehensive minimum cumulative resistance map. It gets four safety grade standard variance partition graph according to half standard variance classification method. Finally determine the ecological "source" and comprehensive resistance, combined with MCR model, set up comprehensive ecological security pattern figure in Yunyang district from 2006 to 2015 (figure III).

\section{ECOLOGICAL SECURITy PARTITION AND SUgGESTION}

\section{A. Ecological Security Partition}

According to figure III, using GIS spatial clustering analysis method divides ecological security grade of Yunyang district into high safety areas, middle safety areas and low safety areas. Figure III shows that the status of the ecological security composite in Yunyang District is higher. Most areas are high level of security, low safety areas are relatively little. High security area accounts for $57.2 \%$ of the total area of the study area, middle security area accounts for $30.5 \%$, and low safety area accounts for $12.3 \%$.

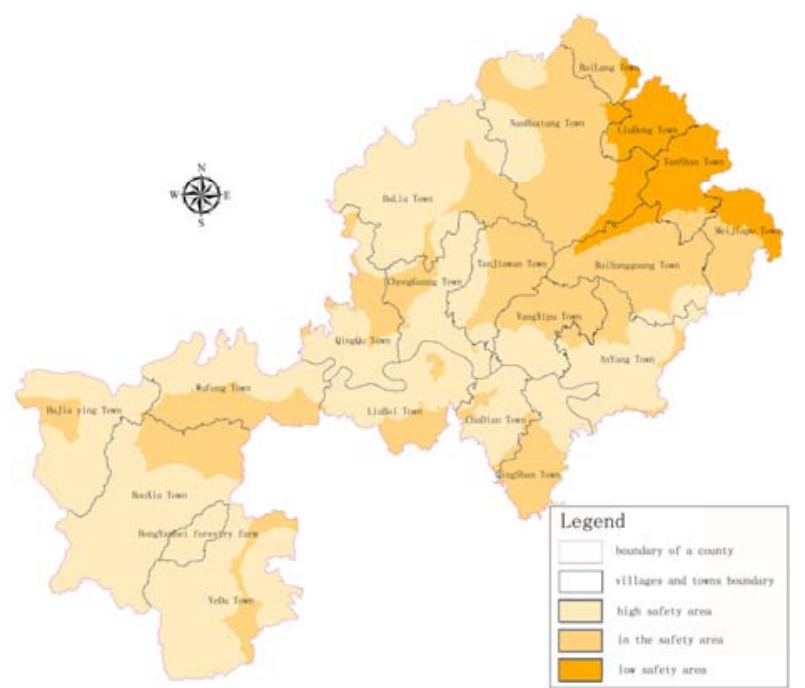

FIGURE III. ECOLOGICAL SECURITY PARTITION MAP IN YUNYANG DISTRICT

\section{B. Ecological Security Partition Suggestion}

Analyzing a kind of factors about land use dynamic change and landscape pattern difference, and combining with the ecological security zoning maps, make some proposals for ecological restoration and ecological planning in three regions.

High security area should be taken to control and protection of the principle of combining ecological planning. The central city development has to conduct appropriate control, including the speed control and scale control, and reduces human activities on the ecological damage. At the same time, from the perspective of ecological environment protection, focusing on the wetland protection in Danjiangkou reservoir area, the key to strengthen the protection of water resources, nature reserves and forest parks in Hanjiang river, Tao river and Zhu river, further to improve the area's ecological construction.

Middle security area mainly adopts the principle of combination of control and prevention to do ecological planning, controls the ecological land to change other land use, and increases the forest coverage. At the same time, man can carry out ecological forest construction, road forest construction and water forest construction, in order to prevent its change to a lower security.

Low security area mainly takes the principle of combining repair and governance, to continue the implementation of returning arable land to forest, desertification control and ecological engineering for the protection of natural forests, to prevent soil erosion, to do well water ecosystem protection and restoration, soil and water conservation work. Promoting economic development and ecological environment coordinated development, optimizing regional layout, strengthening the control of land development, to promote the combination of regional economic development and ecological environment protection.

\section{REFERENCE}

[1] Pan Jing-hu, Liu Xiao. The continental river landscape ecological security evaluation and structure optimization based on the principal component space and minimum cumulative resistance model in Ganzhou District, Zhangye City [J]. Journal of applied ecology, 2015, 10: 3126-3136

[2] Wu Li-yun, Wu Xiao-qin. The study on urban landscape ecological security pattern in fuzhou, for example [J]. Journal of Changchun normal university (natural science edition), $2010,06: 88$

[3] Liu Zhan-cai. The urban ecological security assessment and warning research on ecological fragile region [D]. Northwest normal university, 2008

[4] Li jing, Meng Ji-jun, Mao Xi-yan. Patterns built of land use ecological security based on the minimum cumulative resistance model - in Zhunger Banner, Erdos City [J]. Journal of Beijing university (natural science edition), 2013, 04:707-715

[5] Campobello KR, Bartell SM. Ecological Models and Ecological Risk Assessment [A]. In: Newman MC, Strojan CL (eds). Risk Assessment: Logic and Measurement [C]. Michigan: Ann Abrbor Press, 1998

[6] Li Zong-yao, Yang Gui-shan, Dong Ya-wen. The ecological security pattern construction in rapid economic development area along the Yangtze river in Anhui[J]. Journal of natural resources, 2007,01:106-113

[7] Chen Dong-jing, Xu Zhong-min. The ecological security evaluation research in northwest continental river basin - in Zhangye City of middle Heihe river basin[J]. Journal of arid geography, 2002,03:219-224

[8] Yu Xiao-gan. Ecological security problems and Suggestions in Yangtze river basin [J]. Journal of natural resources, 2002,17 (3) : 294-298 